\title{
An exercise in decision support modelling for islands: a case study for a 'typical' Mediterranean island
}

\author{
Anna Tsoukala \\ University of the Aegean, Mytilini, Greece \\ mard16004@marine.aegean.gr \\ loannis Spilanis \\ University of the Aegean, Mytilini, Greece \\ ispil@aegean.gr
}

Isabel Banos-González

University of Murcia, Murcia, Spain

isabanos@gmail.com

Julia Martínez-Fernández

University of Murcia, Murcia, Spain

juliamf@um.es

\section{Miguel Angel Esteve-Selma}

University of Murcia, Murcia, Spain

maesteve@um.es

and

George Tsirtsis (corresponding author)

University of the Aegean, Mytilini, Greece

gtsir@aegean.gr

\begin{abstract}
Decision support for island management must be based on quantitative tools able to integrate the natural, economic, and social environment, including the effects of recent climate change. In this context, a decision support framework is proposed, characterized by generality and flexibility, to be adapted to the specific characteristics of each island. The framework includes: (a) compilation of existing information and organization in a DPSIR framework; (b) selection of the main economic activities; (c) calculation of environmental, economic, and social indicators through models; (d) development of scenarios for future evolution; and (e) ranking for their preferability using a multicriteria methodology. Scenario development and weighting of indicators and criteria can be based on stakeholders' and public views collected through questionnaires. The proposed framework is applied to a 'typical' fictitious Mediterranean island where tourism, services, and low-rate agriculture are the main economic activities. Mid- and long-term (including climate change) scenario analyses are performed as an exercise with three scenarios expressing different policies in terms of economic and environmental priorities. Advantages and limitations of the proposed framework for real-world applications are discussed.
\end{abstract}

Keywords: climate change, models, multicriteria analysis, public participation, scenarios, sustainability

https://doi.org/10.24043/isj.62

(C) 2018 - Institute of Island Studies, University of Prince Edward Island, Canada. 


\section{Introduction}

Islands are complex dynamic systems with clear physical boundaries (Petridis, 2012; Stratford, 2008) and strongly interacting natural, social, and economic components. They are characterized by fragility and vulnerability (Hay, 2013; Stratford, 2008), considering all aspects of their environment. Sustainable growth and integrated management of coastal zones and islands received the attention of many researchers worldwide. Initially research was focused on conservation and management of natural resources aiming to protect local or national economies (e.g., Farhan \& Lim, 2010; Krelling et al., 2008; Nadin et al., 2008; Stepanova, 2015). The intensive growth of tourism and recreational activities during the recent decades (Christofakis et al., 2009; Ghermandi, 2015) also imposed the need to preserve tourist destinations, and protect cultural heritage and quality of life. For European islands in particular, integrated management has been attempted, for example, in the Canary Islands (Banos-Gonzalez et al., 2015, 2016a, 2016b) and some Greek islands (Spilanis et al., 2009; Petridis, 2012). Various models were used to identify and calculate interactions between sustainability indicators and causal factors. The goals were to ensure a sustainable future with public participation and to achieve different levels of implementation based on local or national approaches, along with system understanding and support of decision-making. Although all these approaches use a common strategy, the tools are different and not generally applicable. Most of them are case-specific, focused on individual characteristics of islands, therefore not flexible and adaptive enough to be generally implemented (de Kok et al., 2015).

Integrated management is considered as an adaptive process with separated phases, such as problem identification, formulation, implementation, and evaluation (Farhan \& Lim, 2010; Perez-Cayeiro \& Chica-Ruiz, 2015). Selection of the appropriate indicators advances the effectiveness of implementation at each phase and supports the quantification and simplification of information that is not always apparent (Bowen \& Riley, 2003). Indicators must have certain characteristics, among which they must (a) supply understandable information to decision-makers; (b) measure the progress in terms of a target; (c) indicate trends in space and time; and (d) be generally applicable and conform with available thresholds and regulations (Pickaver et al., 2004). Integration of such indicators into dynamic models allows the visualization of their change over time and the assessment of how any variation in one indicator may lead to a series of responses on other indicators, showing in this sense the ongoing changes in the processes they represent (Moldan et al., 2012). Moreover, the models facilitate the recognition of interactions among interconnected subsystems driving the behaviour of dynamic systems, by means of causal relationships, feedback loops, delays, and other processes (Banos-González et al., 2015). Dynamic models also represent useful learning tools that enhance system understanding and facilitate involvement of non-technical stakeholders in the decision-making process, a key issue in integrated management (Deboudt, 2012; Le Gentil \& Mongruel, 2015; Perez-Cayeiro \& Chica-Ruiz, 2015; Soriani et al., 2015; Stojanovic et al., 2004).

Decision Support Systems (DSS) are tools able to assist, facilitate, and support decisionmaking (Farhan \& Lim, 2010), coping with multiple aims and incorporating quality and development indicators. They must also take into account local carrying capacities, meet the flexibility and complexity of dynamic systems, conduct multicriteria analysis, and integrate multidisciplinary approaches (Farhan \& Lim, 2010). In this sense, they may form the appropriate tools for supporting policies in evolving environments (Marotta et al., 2011) such as islands or coastal zones. Although the implementation of those policies strongly depends on the administrative status of islands since final decisions are not always taken locally, DSS form the most appropriate consultation tools to impose guidelines for a sustainable future and support mid- and long-term decision's depiction (Van Kouwen et al., 2008; Varghese et al., 2008). Long-term planning is especially important when mid-term decisions have long-term 
consequences, making it possible to visualize key issues that may otherwise be missed. The use of dynamic models inside DSS allows decision-makers to anticipate the long-term consequences of their decisions and actions, as well as the unintended consequences and uncertainty of policies and strategies (Kelly et al., 2013). For this purpose, scenario development, including policy options, is one of the major tools used to visualize and compare the potential outcomes of a variety of policies to meet sustainability objectives, as well as to anticipate the long-term consequences of scenarios, policy decisions, and actions (BanosGonzález et al., 2016a).

Islands as fragile socioeconomic systems are expected to be more vulnerable to recent climate changes, mostly associated with changes in air temperature and precipitation. In Integrated Coastal Zone Management (ICZM), climate change has been already identified as one of the main priorities (Farhan \& Lim, 2010), considering that it will affect population growth, is likely to reduce per capita water resources (Kostopoulou et al., 2014), change energy consumption and human comfort (Kostopoulou \& Jones, 2005), and, finally, increase loss of human lives (Kostopoulou \& Jones, 2005). In the Mediterranean region, in particular, air temperature shows a significant increase, whereas precipitation decreases, showing seasonal differentiation (Brunetti et al., 2004; de Luis et al., 2010; Giannakopoulos et al., 2011; Kostopoulou \& Jones, 2005; Kostopoulou et al., 2014; Spyropoulou et al., 2013). As a result, there is an increased probability of extremely warm days and significant trends in the maximum number of consecutive dry days (Kostopoulou \& Jones, 2005; Kostopoulou et al., 2014) with direct impacts on the economy. For instance, extremely high temperatures will affect tourism and agriculture, the two main economic activities for coastal zones and islands in the Mediterranean Basin (Giannakopoulos et al., 2011; Kostopoulou \& Jones, 2005), finally leading to economic losses and immigration (de Luis et al., 2010).

In the present paper a framework for decision support in islands' management is introduced, approaching islands as complex dynamic systems. The framework includes: (a) compilation of the existing information for the physical, social, and economic environment of an island, including climate trend analysis; (b) identification of the main system drivers using the DPSIR framework; (c) selection of an appropriate set of sustainability indicators; (d) development of models quantifying relations, interactions, and feedback mechanisms; (e) development of scenarios and policy options for mid- and long-term forecasting; (f) application of multicriteria analysis where stakeholders' views and political and social priorities may be accounted for. This framework is general for wide applicability, however flexible enough to include distinct characteristics of the physical, socioeconomic, or cultural environment of an island. The proposed framework is applied as an exercise on a 'typical' Mediterranean island and (a) the current state of the island is depicted; (b) a mid-term (10 years) scenario analysis is performed; (c) effects of climate change are considered by comparing the current state and a typical year in the future (long-term scenario analysis); and (d) a multicriteria analysis is applied aiming to highlight points where political priorities, stakeholders', and social views may be incorporated.

\section{Methodology}

\section{Outline of the proposed framework}

The proposed framework for decision support in management of islands is based on a similar approach developed for Mediterranean coastal lagoons (Zaldivar et al., 2006). Following the perspectives emerging from the science of sustainability, in the current approach there are two interconnected but clearly distinctive components (Figure 1). 
(a)

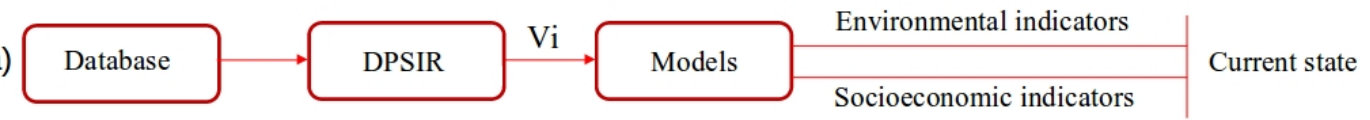

(b)

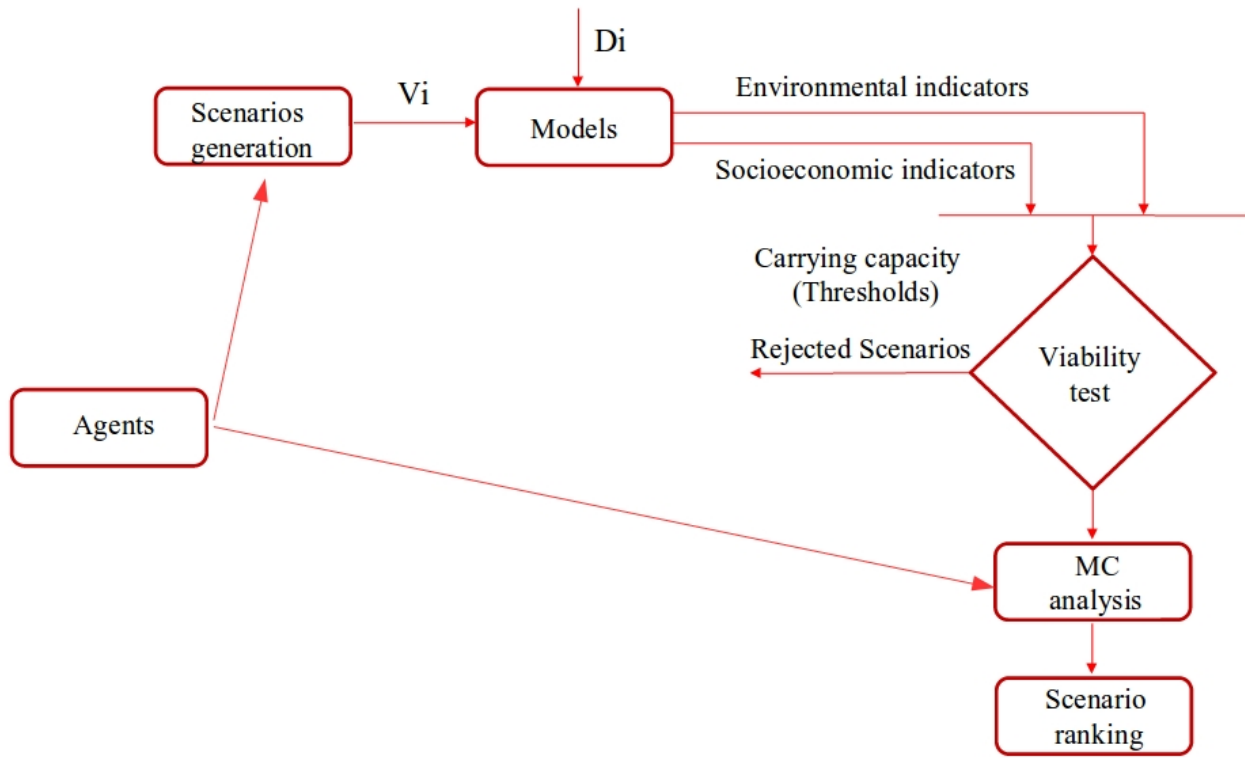

Figure 1: Flow diagram of the proposed integrated framework for the management of islands: (a) assessment of current state and (b) development and ranking of scenarios for mid- and long-term analysis.

The first component refers to the description of the system, using all necessary data and models. The second component (the DSS) refers to the selection of objectives, criteria, and valuation procedures to assess different scenarios and prioritize among policy options. This second component should be based on the knowledge provided by the first component (model results assessed in terms of indicators and thresholds) and on a wide involvement of stakeholders, policy-makers, and citizens, by means of a participatory process. In this sense the current state of the island under consideration is firstly depicted (Figure 1a). A database is compiled including information for the natural, economic, and social environment of the island. Based on this information, the main economic sectors are identified using the DPSIR (Drivers-Pressures-State-Impact-Response) framework and each sector is expressed through a characteristic variable Vi measuring the production capacity or the real production of the main activity. Models (simple linear relations or more complex models) based on those variables and appropriate coefficients are then used to estimate a number of indicators expressing the performance of each activity: economic, socio-demographic, and environmental. Then the total performance (the current State) of the whole system is assessed. There are two potential sources of uncertainty in the above calculations: (a) uncertainties in characteristic variables due to data collection methods from national statistical authorities; and (b) uncertainties in coefficients since they represent averages including variation due to differences in behaviour or practices within each activity (e.g., Erb et al., 2013). For the mid-term evolution of an island (e.g., for a decade), scenarios are developed by changing characteristic variables and coefficients (Figure 1b). Those changes may reflect local views of the public, stakeholders, or politicians, as well as external trends at the national or international level affecting the socioeconomic system of the island. Long-term analysis can also be performed by comparing the current state with a typical year in the future in which climate changes are incorporated 
through a number of external variables Di. Those external variables can be changes in precipitation height and frequency, or rise in air temperature. A viability test is performed prior to the multicriteria evaluation aiming to reject scenarios that are not acceptable in terms of environmental protection or socioeconomic growth. Ranking of viable scenarios from the most to the least preferable is then carried out to support decision-making, using a multicriteria choice methodology. Agents, institutional or local, are involved in the multicriteria analysis through the assignment of weights. A prototype of the proposed framework for integrated management of islands has been developed in $\mathrm{R}$ code ( $\mathrm{R}$ Core Team, 2013).

\section{Implementation in a 'typical' Mediterranean island}

The above described framework is implemented in a 'typical' fictitious Mediterranean island with a population of about 30,000 inhabitants and an area of $500 \mathrm{~km}^{2}$. The economy of most of those islands is based on tourism (Banos-Gonzalez et al., 2015, 2016a; Petridis, 2012; Spilanis et al., 2009), but also on low rate agricultural, stock-breeding, fisheries and industrial activities (Spilanis et al., 2009; Petridis, 2012). Since services including administration, education, health care, energy and water supply, and solid waste treatment have to be provided to each island on its own due to transport limitations (Spilanis et al., 2013), the services' sector engrosses a large number of employees and largely contributes to the local economy.

Trying to resolve interactions, conflicts, and feedback mechanisms in the environment of the island (natural, economic, and social), the DPSIR (Drivers-Pressures-State-ImpactResponse) framework is applied. The economic activities on the island are considered as the main Drivers $(\mathrm{D})$. Pressures $(\mathrm{P})$ originate from those drivers, affecting natural resources (e.g., water, energy) and producing pollution and contamination, which in turn alter the State (S) of natural resources. Accordingly, changes in state have positive or negative consequences which are defined, evaluated, and described as Impacts (I). Those impacts lead to Responses $(\mathrm{R})$, undertaking of actions and policies coping with the effects on the natural and socioeconomic environment. For the typical island, the Drivers are the main economic sectors: (i) agriculture, (ii) stock-breeding, (iii) fisheries, (iv) industry, (v) tourism, (vi) construction, and (vii) services, each one expressed through a characteristic variable Vi (Table 1). Each sector can be further divided into subsectors aiming to increase the resolution of the model. For example, fisheries, aquaculture, and shellfish harvesting can be the subsectors for fisheries and olive refineries, milk dairies and wineries, the subsectors for industry in a Mediterranean island.

Table 1: Main economic sectors (Drivers) and their corresponding characteristic variable for the 'typical' Mediterranean island.

\begin{tabular}{cc}
\hline Economic Sectors & Characteristic variables $(\mathrm{Vi})$ \\
\hline Agriculture & Cultivated area \\
Stock-breeding & Number of animals \\
Fisheries & Catch \\
Industry & Raw material \\
Tourism & Nights spent \\
Construction & Number of employees \\
Services & Number of employees \\
\hline
\end{tabular}

Economic activities consume water and energy, produce solid wastes and pollution (e.g., $\mathrm{N}$ and $\mathrm{P}$ loading, $\mathrm{CO}_{2}$ ), and cause biodiversity loss in the island. The state of the island is affected, population can be increased or decreased, per capita income and employment changed; land use also changes and there are alterations in the quality of agricultural, fishing, 
and industrial products. Those effects are expressed through a number of environmental and socioeconomic indicators. In the current implementation, ten indicators were used (Table 2).

Table 2: Environmental, economic, and social indicators used in the current implementation of the integrated framework for the 'typical' island. HDI is a synthetic index based on unemployment rate, life expectancy, and poverty rate (or income per capita).

\begin{tabular}{cc}
\hline Category & Indicator \\
\hline Environmental & Water consumption/water availability \\
& Energy consumption \\
& $\mathrm{N}$ loading \\
& $\mathrm{P}$ loading \\
& $\mathrm{CO}_{2}$ emissions \\
& Solid wastes \\
& Land use change/Biodiversity loss \\
\hline Economic & Employment \\
& Income \\
\hline Social & Human Development Index (HDI) \\
\hline
\end{tabular}

Indicators are calculated for each sector or subsector based on its characteristic variable and appropriate coefficients, using models, either simple linear relations or more sophisticated dynamic models. As an example of simple linear relationships, water consumption can be calculated by multiplying cultivated area by the amount of water used for irrigation per unit area. Income from tourism can be estimated by multiplying nights spent by tourist expenditure. A more complex watershed model is used for the calculation of nitrogen and phosphorus loading from point and non-point sources, already described in detail in a previous paper (Spyropoulou et al., 2013). These loadings can be further used to estimate marine pollution or the risk to overcome related thresholds. The island is firstly divided into watersheds. The model estimates the amount of run-off and nutrients (dissolved inorganic nitrogen and phosphorus) leached from each watershed, after a rainfall event on a daily basis according to land uses and the local topography. Loads from point sources (industry, stockbreeding, urban wastes) are also taken into account and the total amount of nitrogen and phosphorus or the amount flowing into the receiving water bodies is used as environmental indicator. Moreover, renewal time estimated from hydrodynamic models, or amount of erosion can be used as indicators in the proposed framework. The same holds for other socioeconomic indicators estimated by simple or more complex relationships. A detailed description of the model equations used in the current implementation is given in Appendix 1. The full set of indicators is finally used to depict the current state of the island under consideration.

Scenarios are then developed for the future evolution of the island, either for mid- or long-term analysis. For mid-term analysis (e.g., one decade), three prospective scenarios of environmental and socioeconomic changes were deployed in the current implementation, their basic context already described in a previous paper (Kontogianni et al., 2007). The baseline or reference scenario (Business as Usual, BAU) is where prevailing trends are continued without special interventions. This trend is expressed for the 'typical' island through a slow rate of annual increase in economic activities, paying less attention to environmental protection. In the second scenario (Policy Targeted, PT), policies for a rather fast economic growth are encouraged, whereas environmental protection is also taken into account more actively. Finally, the Deep Green (DG) scenario is mostly focused on environmental protection and environmentally friendly economic growth. These scenarios are quantified in the models by changing, on an annual basis, either the characteristic variables 
of each sector, or the coefficients, or both. For example in a PT scenario, cultivated area may increase aiming to economic growth (e.g., $0.5 \%$ per year); however, the amount of water used for irrigation can decrease (e.g., $0.2 \%$ annually) for environmental protection. This decrease may be more pronounced in a DG scenario.

Direct and indirect mechanisms of dependence and feedback are also taken into account in the evolution of the island. For instance, industrial raw material originates from agricultural (e.g., olive oil and wine) or stock-breeding (e.g., milk) activities. Employment in the services sectors depends on the previous two-year trend in income, whereas population changes are connected with the trends of economic growth and social welfare (the latter expressed with HDI). More details about the dependencies and feedback mechanisms used in the current implementation are given in Appendix 2. Scenarios are then simulated for the mid-term analysis on an annual basis and the evolution of various indicators in time (e.g., for a decade) is estimated. Indicators can be integrated into three criteria-environmental, economic, and social-each one being a weighted sum of the corresponding indicators. For example, in the current implementation, the environmental criterion is a weighted sum with equal weights of all environmental indicators, and the same holds for the economic and social criteria. Thereafter, the evolution of each criterion in time is used for a qualitative comparison of scenarios.

For the long-term analysis including climate change, scenarios are simulated for one typical year in the future. Climate changes can be easily incorporated in the models by, for example, reducing the height and frequency of rainfall or increasing air temperature. Single values are estimated for each indicator and scenario, and those values are compared with the corresponding indicators of the current state of the island. A similar comparison can also be made for criteria, as described in the previous paragraph.

A viability test can be applied for both mid- and long-term analysis prior to the multicriteria evaluation. This test aims to identify scenarios that are not acceptable in terms of environmental protection or socio-economic growth. To perform the test, thresholds are set for each indicator expressing carrying capacities, legal standards, or reference values originating from the historical evolution of the island. Indicators that violate the limits are identified and the corresponding scenarios are considered as non-viable and rejected from further analysis.

Finally, ranking of acceptable scenarios is performed by applying a multicriteria choice methodology. In the current implementation, Analytic Hierarchy Process (AHP) was used. AHP, originally developed by Saaty (1980), evaluates different alternatives (scenarios) based on pairwise comparisons of criteria, according to their importance. In this sense, a final score is attributed to each scenario, and scenarios are ranked from the most to the least preferable. This ranking is on an annual basis in the mid-term analysis, whereas for the long-term analysis ranking is based on the single values calculated for each scenario.

It is essential to involve different agents, institutional or local, in the decision-making process. Stakeholders' views and political and social priorities can be collected through a variety of methodologies, including workshops and meetings with stakeholders, and questionnaires. A thorough analysis of questionnaires can be used (a) to identify the appropriate set of indicators; (b) to define the number of scenarios; (c) to assign changes in characteristic variables and coefficients in scenarios' development; (d) to assign weights to indicators inside criteria; and (e) to define the relative importance of criteria.

\section{Results: a case study for a 'typical' fictitious Mediterranean island}

The proposed integrated framework for decision support in islands' management was applied on a typical or prototype Mediterranean island, integrating most of the common characteristics of Mediterranean islands, including limited natural resources, small size, isolation, and local economy mostly based on tourism and services, but also on small-scale agriculture, stock-breeding, fisheries, and industry (Spilanis et al., 2009). More than half of 
the residents are financially inactive, whereas the majority of employment is in services, commercial as retail and non-commercial as public services. The current state of the island can be described by running the model and estimating the environmental and socioeconomic indicators. An important environmental indicator for Mediterranean islands is water consumption per sector, shown in Figure 2, where agriculture and households are the main consumers. Similar graphs can also be plotted for the subsectors of a sector if a more thorough analysis of the indicator under consideration is needed.

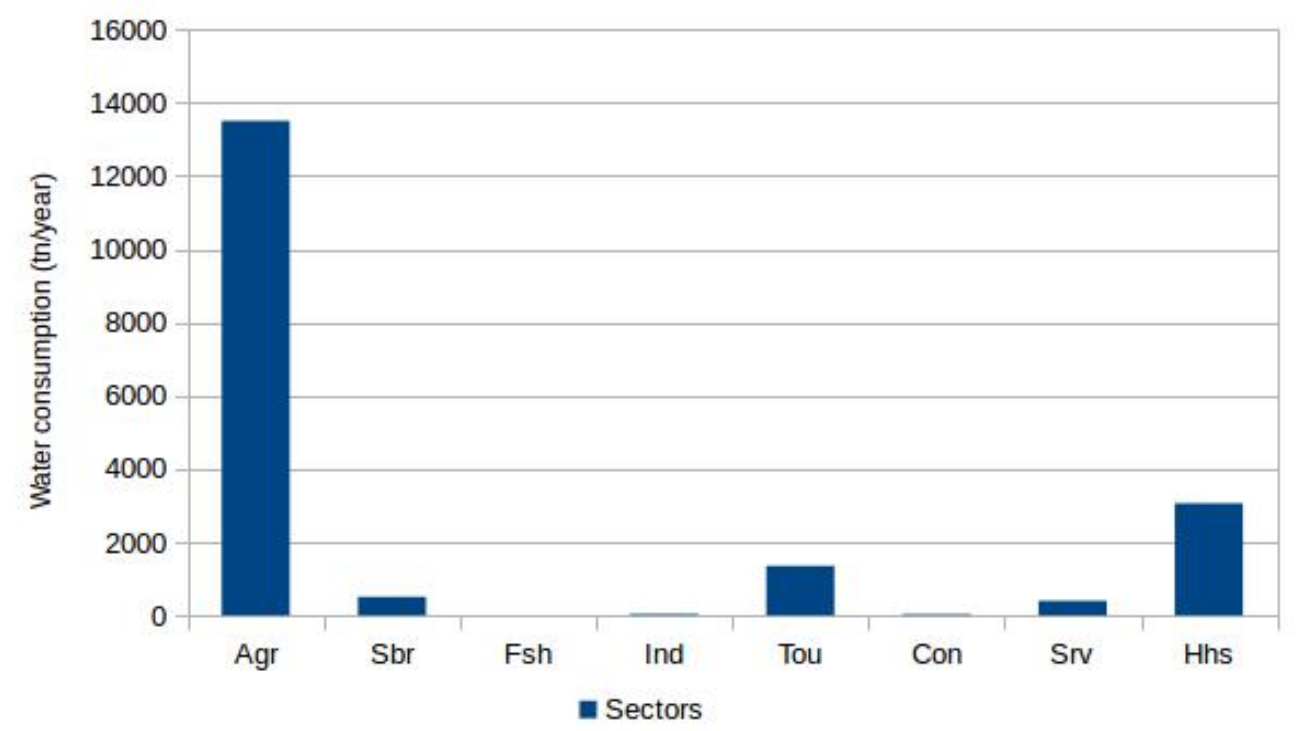

Figure 2: Water consumption (tn/year) per sector in the typical Mediterranean island estimated by the model. Agr: Agriculture, Sbr: Stock-breeding, Fsh: Fisheries, Ind: Industry, Tou: Tourism, Con: Constructions, Srv: Other Services, and Hhs: Households.

Considering local economy, income per sector can be estimated by the model (Figure 3). Tourism and services are the main sources of income for the typical island, the same holding for most of the Mediterranean islands.

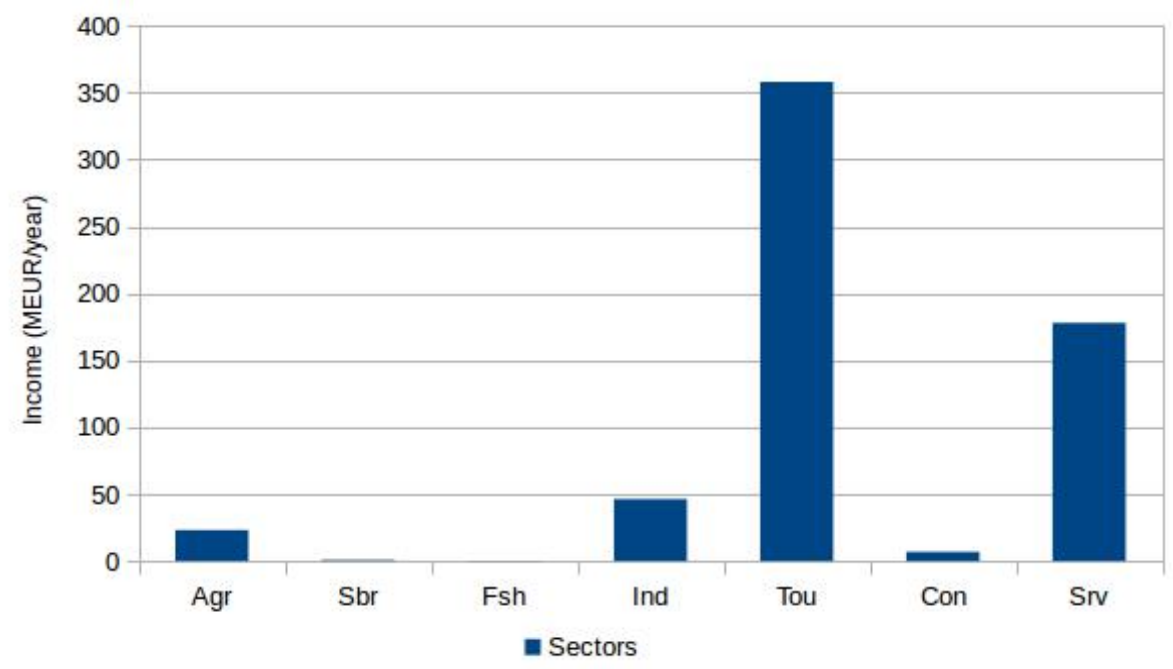

Figure 3: Income (MEUR/year) per sector in the typical Mediterranean island estimated by the model. Agr: Agriculture, Sbr: Stock-breeding, Fsh: Fisheries, Ind: Industry, Tou: Tourism, Con: Constructions, Srv: Other Services, and Hhs: Households. 
Taking a step forward, a mid-term (for a decade) scenario analysis was performed. Three scenarios were developed and tested for the typical island, expressing the current trends (Business As Usual, BAU), emphasis on economic growth (Policy Targeted, PT), and emphasis on environmental protection (Deep Green, DG). The evolution of indicators during the decade is the result of the simulation. Synthetic indicators can also be calculated, used as criteria in the multicriteria analysis, such as the economic criterion, being a weighted sum of the economic indicators, income and employment, with equal weights in the current case study. The evolution of employment (number of employees) and the economic criterion are shown in Figure 4. Employment is decreasing for almost three years in all scenarios due to the depression of the local economy which was incorporated in the scenarios for two years. This depression follows the corresponding trend at the national level since the island is an open system not isolated from the rest of the world. The decreasing trend is then reversed for all scenarios and economic growth is presumed, being more pronounced for the PT and DG scenarios (Figure 4a). A similar trend is observed for the economic criterion, being an average of the income and employment (Figure $4 b$ ).

(a)

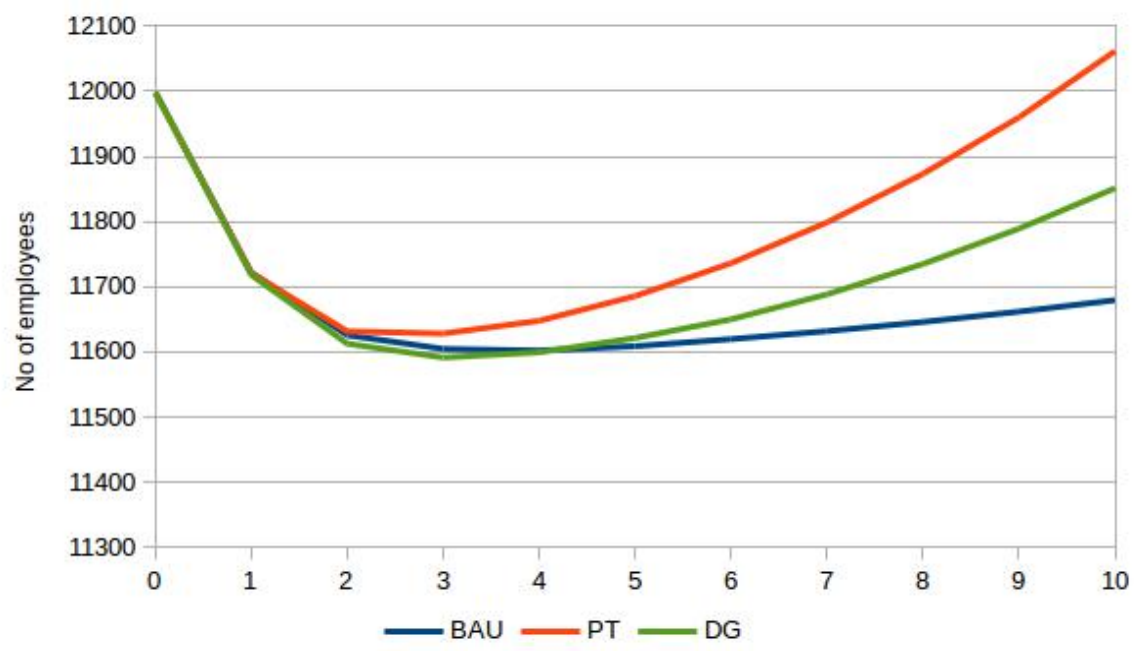

(b)

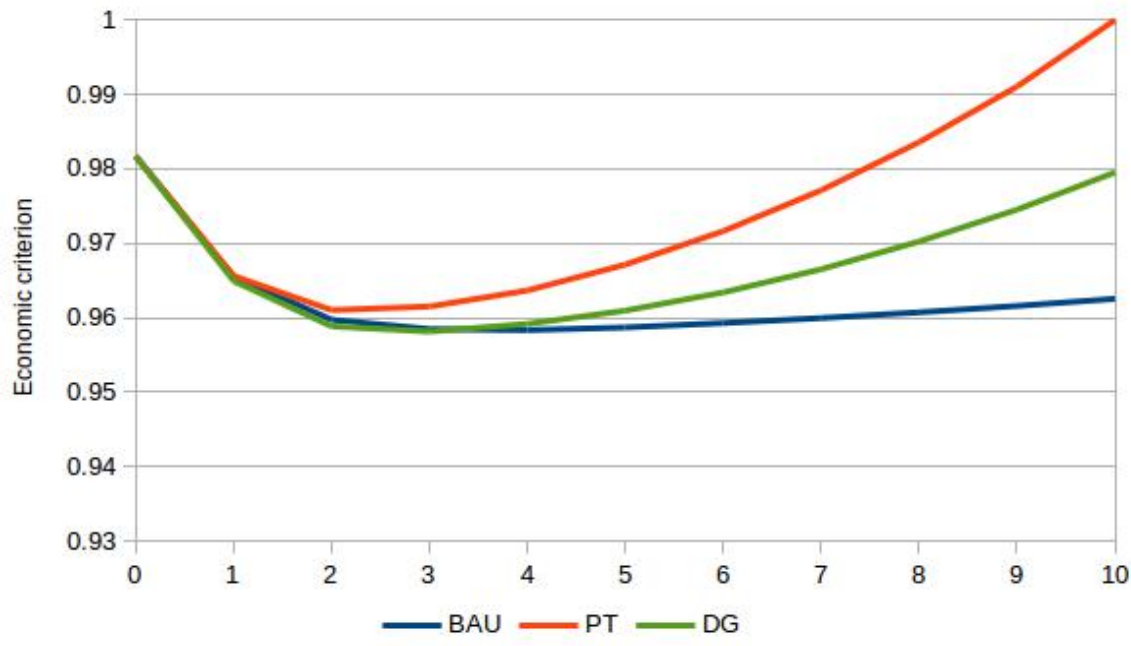

Figure 4: Mid-term scenario analysis: Evolution of (a) employment (number of employees) and (b) economic criterion (weighted sum of income and employment with equal weights) during a decade for BAU (in blue), PT (in red), and DG (in green) scenarios. 
Finally, the Analytic Hierarchy Process (AHP) was applied to rank scenarios according to their preference based on environmental, economic, and social criteria. Final ranking with equally weighing criteria is shown in Figure 5. It is important to note that according to the methodology, the sum of the three scores is always equal to one, so only pairwise comparisons are possible, not taking into account absolute values and differences. BAU scenario has the lowest score throughout the decade. DG is slightly more preferable than the PT during the first two years of the analysis; however, the latter is more preferable in the long term.

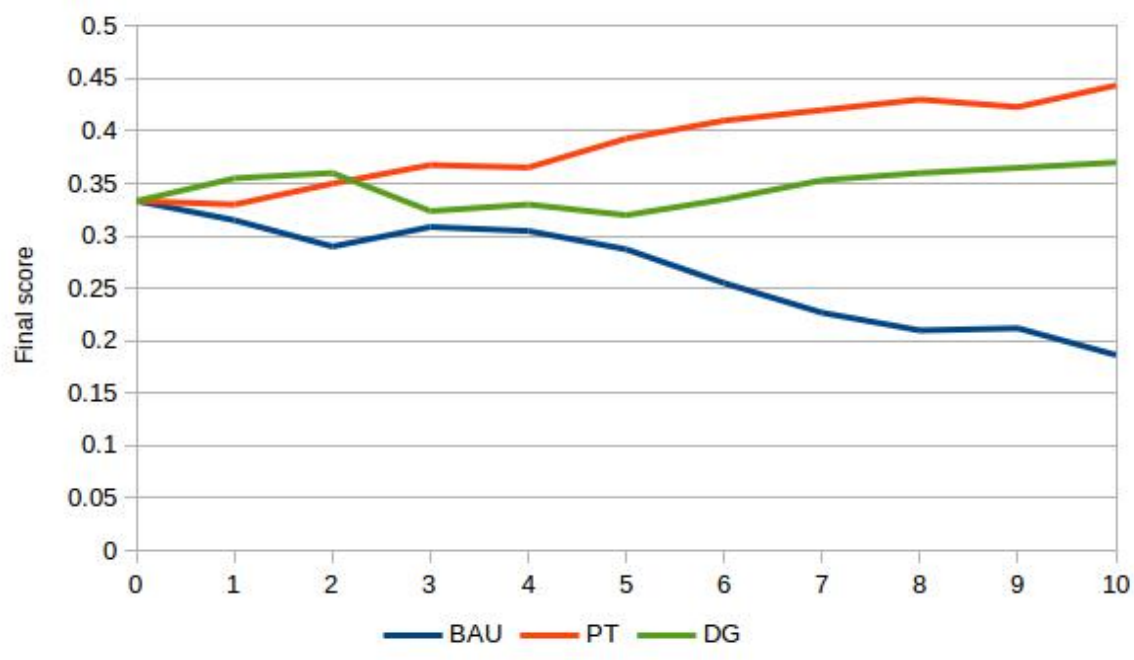

Figure 5: Mid-term scenario analysis: Evolution of Final score (with equal weights on environmental, economic, and social criteria) during a decade for BAU (in blue), PT (in red), and DG (in green) scenarios.

For the long-term analysis aiming to incorporate climate changes, the three scenarios were simulated for a future year and results were compared with the current state. According to recent climatological studies for the Mediterranean basin (Giannakopoulos et al., 2011; Kostopoulou et al., 2014), a decrease in annual rainfall of $10 \%$ and an increase in air temperature of $10 \%$ are plausible. These changes affect the water budget due to the decrease of precipitation and the increase of evaporation. Increase of air temperature, especially in summer, also affects economy (tourism and agriculture) and social well-being. Simulation results for the future year include single values of all indicators and criteria for each scenario, which can be compared with the corresponding values for the current state of the island. As an example, population growth and final ranking of scenarios are shown in Figure 6. Equal weights were assigned to the three criteria-environmental, economic, and social-in the multicriteria analysis. 
(a)

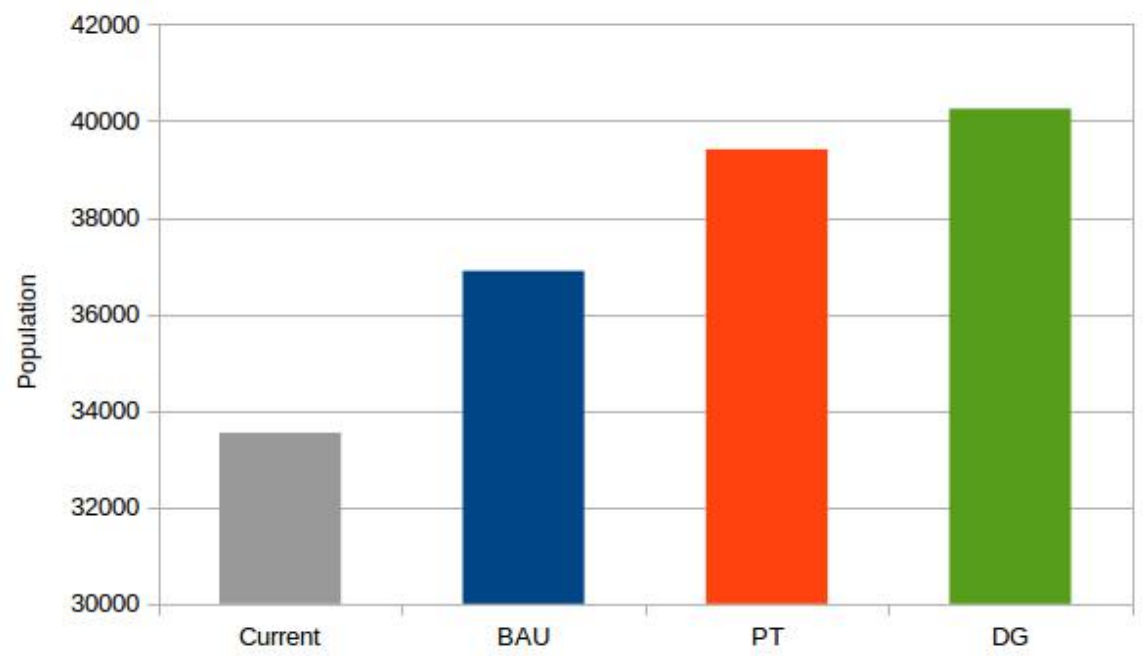

(b)

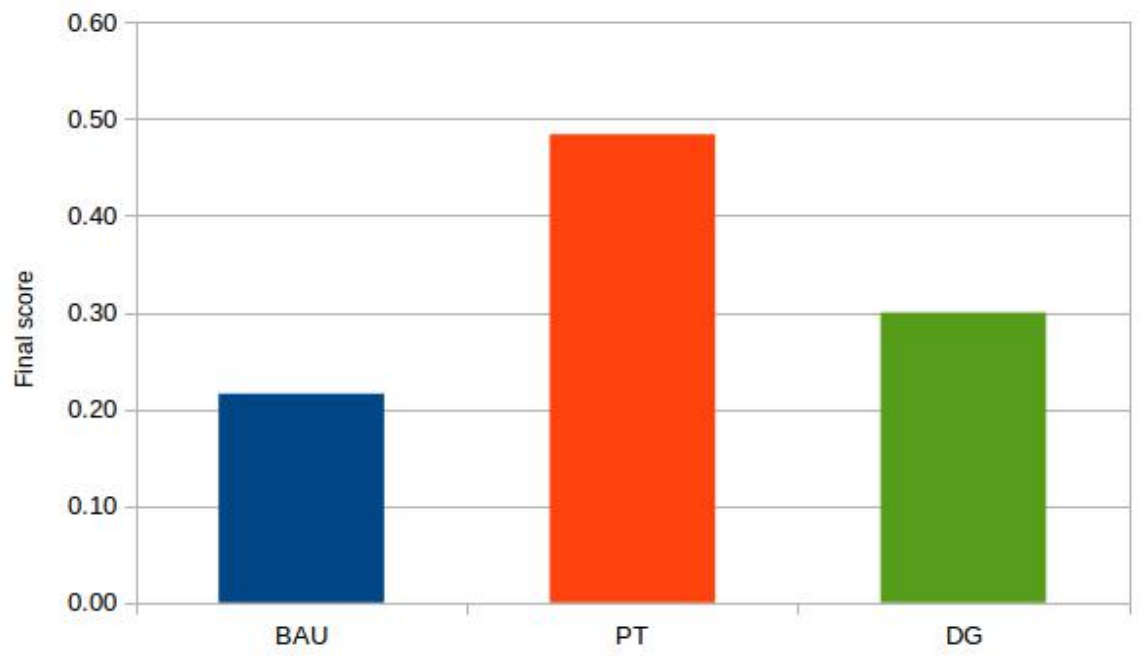

Figure 6: Long-term scenario analysis: Comparison of (a) population and (b) final score for the current state (in grey) and the future year as estimated by the three scenarios (BAU in blue, PT in red, and DG in green).

Population shows an increase in the future which is more pronounced for the Deep Green scenario. Population change is related both to the trends of economic growth and social welfare. It seems therefore that environmental protection in the DG scenario increases social welfare that in turn out-competes possible higher economic growth in favour of the PT scenario. However, taking into account all criteria with equal weights, PT scenario is more preferable than DG, whereas BAU expressing current trends without significant interventions is the least preferable in long term.

\section{Discussion}

Integrated management of islands, taking into account climate change and using information technology tools, must be a first priority in decision-making for politicians, local and institutional stakeholders, and researchers, based on the long experience from coastal zone management (Van Kouwen et al., 2008). The proposed framework is characterized by generality to be applied to any island, but also by flexibility to be adapted to the specific environmental, economic, social, or cultural characteristics of each island. The framework 
approaches islands as dynamic systems, highlights their main components (physical environment, economy, society, cultural identity, and transport) and develops quantitative relationships to study interactions, dependencies, and feedbacks, as well as input and output flows. Those flows might be in terms of currency, people, goods, or energy, since islands are open systems that continuously interact with the external environment at the national and international levels. The framework is divided into separate phases, some of which should include public and stakeholders' participation, as the definition of indicators and sustainability goals, prioritization of economic sectors, and ranking of scenarios. Limits set by carrying capacities in terms of environmental, economic, social, and cultural aspects, or by the existing legislation, in the form of thresholds for indicators, can also be taken into account and, accordingly, reject scenarios overcoming those limits. The proposed framework can be used for consultation and for the assessment of possible outcomes of policy options, although final decisions and implementation always depend on the administrative authorities of each island, either local, regional, or national.

Spatial resolution and capability to develop spatially explicit scenarios is desirable in the coastal zone (Van Kouwen et al., 2008), and moreover in islands' management. Multi-agentbased models can be used to study problems integrating social and spatial aspects (Bousquet \& Le Page, 2004), including human behaviour, an important steering factor for management (Boulanger \& Brechet, 2005; Otter, 2000). Theoretically there is no limitation in spatial resolution for the proposed management framework, provided that information is available, for variables, coefficients, mechanisms, and priorities, even at a small-scale level. However, there is always lack of information at low spatial scales, especially for the socioeconomic data and therefore spatial aggregation is almost always necessary (Van Kouwen et al., 2008; Le Gentil \& Mongruel, 2015). National statistical authorities usually collect data for administrative units, as municipalities, prefectures, or regions; therefore a compromise has always to be made between spatial resolution and available information. In the case study of the 'typical' island, the lower spatial unit was the watershed for which the water budget was studied; whereas the rest indicators were calculated at the whole island level, considering the island as the administrative unit. This hybrid approach is proposed for future use as a compromise between processes that have to be studied in low resolution and availability of data. Coastal hydrodynamics or biodiversity losses are often studied with spatially explicit lowresolution models which are time-consuming to set and run. Such models can be run off-line and their results be aggregated in single indicators able to be incorporated in the management framework and taken into account in current state evaluation and scenario testing.

A fundamental difficulty in managing long-term and sustainability decisions is uncertainty. Since the future is uncertain, Uusitalo et al. (2015) stated that it is impossible to predict with certainty the result of each management decision. Moreover, complex models with many interactions among individual sources of uncertainty can increase the overall model uncertainty (Perz et al., 2013). Therefore, there is a need to identify potential sources of uncertainty and to quantify their impact on model outputs and on the evaluation of policy options. Among the tools to understand and take into account uncertainty, an extensive sensitivity analysis can be performed, for example, by means of Monte Carlo simulations. The sensitivity analysis allows a detailed assessment of model robustness and, therefore, the reliability of the model outputs, as well as the explicit quantification of the specific uncertainty associated to each model outcome under the considered scenarios and policies. The consideration of uncertainty is important since it modifies the conclusions regarding whether some objectives are achieved or whether certain sustainability thresholds might be exceeded. For example, some indicators might not exceed their thresholds when mean values (of Monte Carlo simulations) are considered, but such thresholds might be overcome when the whole uncertainty range of the concerned indicator is taken into account. The proposed modelling tool can be easily adapted to be used for backcasting the evolution of a real island, for example, one decade. In this sense, 
Monte Carlo simulations can be used to assess the sensitivity of indicators resulting from uncertainties, either in characteristic variables due to the methods of collection or in coefficients representing averages resulting from different behaviours and practices.

In terms of interpretation of the indicators and in order to represent a useful tool for public communication and assessment of scenarios and policy options, a quantitative notion of what is acceptable for sustainability (a threshold) is needed (Banos-González et al., 2016b). A threshold may be a background value or a meaningful reference value for something like the irreversibility of the socio-ecological system. Depending on the nature of the indicator, either environmental or socioeconomic, threshold values can be provided by mandatory legal standards, guidelines from different institutions, benchmarking (best practices and experiences from other islands or socio-ecological systems), and the own background of the island (historical values as reference). The establishment of thresholds for every indicator is a clear step forward in sustainability since they represent a reference for decisions allowing the definition of acceptable ranges of change (Rodríguez-Rodríguez \& Martínez-Vega, 2012). Establishment of thresholds for socioeconomic indicators would also prevent actions of conspicuous sustainability leading to an 'eco-island trap' (Grydehøj \& Kelman, 2017), often resulting from the overweighing of environmental criteria in multicriteria approaches. In the proposed framework, prior to the application of multicriteria analysis, a viability test can be performed: scenarios exceeding existing limits or thresholds, including social or political acceptability, are considered as not viable and rejected from further analysis. Setting sustainability goals and identifying appropriate indicators with their thresholds to monitor progress towards these objectives over time, with the involvement of stakeholders in the whole process, may increase their influence on the adoption and assessment of sustainable policies and practices.

In order to support policies, management tools are used for both backcasting and forecasting (Holmberg, 1998; Robinson, 2003; Van Kouwen et al., 2008). Forecasting through public participation, an inherent characteristic of the proposed framework, is also important to evaluate the effectiveness of the proposed strategies, define alternatives, and optimize policies (Le Gentil \& Mongruel, 2015). Public participation in certain phases of the management framework restricts the drawbacks of participatory activities which are often time- and resource-consuming (Le Gentil \& Mongruel, 2015; Soriani et al., 2015). The selection of stakeholders', politicians', and public views is also crucial (Le Gentil \& Mongruel, 2015), based on appropriately designed questionnaires. Analysis of the information from questionnaires can be used to assign weights to indicators, define the number and content of scenarios by prioritizing economic sectors, and, finally, apply multicriteria analysis. The possibility to include climate changes and forecast possible effects on economy and social wellbeing is an additional important feature, since those changes greatly affect regions with many islands, such as in the Mediterranean (Giannakopoulos et al., 2011; Kostopoulou et al., 2014; Spyropoulou et al., 2013).

\section{Acknowledgements}

Part of this work was supported by the Integrated Program for Island Research (IPIR) of the Program: 'The University of the Aegean, the prominent and driving factor for the economic and social growth of the wide Aegean area' of the Operational Program 'Education and Lifelong Learning', which is co-funded by the European Union (European Social Fund) and National Resources. 


\section{References}

Banos-Gonzalez, I., Martínez-Fernández, J., \& Esteve, M.A. (2015). Dynamic integration of sustainability indicators in insular socio-ecological systems. Ecological Modelling, 306, 130-144. https://doi.org/10.1016/j.ecolmodel.2014.08.014

Banos-Gonzalez, I., Martínez-Fernández, J., \& Esteve, M.A. (2016a). Tools for sustainability assessment in island socio-ecological systems: an application to the Canary Islands. Island Studies Journal, 11(1), 9-34.

Banos-González, I., Martínez-Fernández, J., \& Esteve, M.A. (2016b). Using dynamic sustainability indicators to assess environmental policy measures in Biosphere Reserves. Ecological Indicators, 67, 565-576. https://doi.org/10.1016/j.ecolind.2016.03.021

Boulanger, P.M., \& Brechet, T. (2005). Models for policy-making in sustainable development: The state of the art and perspectives for research. Ecological Economics, 55(3), 337-350. https://doi.org/10.1016/j.ecolecon.2005.07.033

Bousquet, F., \& Le Page, C. (2004). Multi-agent simulations and ecosystem management: a review. Ecological Modelling, 176(3-4), 313-332. https://doi.org/10.1016/j.ecolmodel.2004.01.011

Bowen, R.E., \& Riley, C. (2003). Socio-economic indicators and integrated coastal management. Ocean \& Coastal Management, 46(3-4), 299-312. https://doi.org/10.1016/S0964-5691(03)00008-5

Brunetti, M., Buffoni, L., Mangianti, F., Maugeri, M., \& Nanni, T. (2004). Temperature, precipitation and extreme events during the last century in Italy. Global and Planetary Change, 40(1-2), 141-149. https://doi.org/10.1016/S0921-8181(03)00104-8

Christofakis, M., Mergos, G., \& Papadaskalopoulos, A. (2009). Sustainable and balanced development of insular space: the case of Greece. Sustainable Development, 17(6), 365377. https://doi.org/10.1002/sd.396

de Kok, J.L., Engelen, G., \& Maes, J. (2015). Reusability of model components for environmental simulation: case studies for integrated coastal zone management. $\begin{array}{lllll}\text { Environmental Modelling } \& \quad \text { Software, } & 68,\end{array}$ https://doi.org/10.1016/j.envsoft.2015.02.001

de Luis, M., Brunetti, M., Gonzalez-Hidalgo, J.C., Longares, L.A., \& Martin-Vide, J. (2010). Changes in seasonal precipitation in the Iberian Peninsula during 1946-2005. Global and Planetary Change, 74(1), 27-33. https://doi.org/10.1016/j.gloplacha.2010.06.006

Deboudt, P. (2012). Testing integrated coastal zone management in France. Ocean \& Coastal Management, 57, 62-78. https://doi.org/10.1016/j.ocecoaman.2011.11.004

Erb, K-H., Haberl, H., Jepsen, M.R., Kuemmerle, T., Lindner, M., Müller, M., Verburg, P.H., \& Reenberg, A. (2013). A conceptual framework for analysing and measuring land-use intensity. Current Opinion in Environmental Sustainability, 5(5), 464-470. https://doi.org/10.1016/j.cosust.2013.07.010

Farhan, A.R., \& Lim, S. (2010). Integrated coastal zone management towards Indonesia Global Ocean Observing System (INA-GOOS): review and recommendation. Ocean \& Coastal Management, 53(8), 421-427. https://doi.org/10.1016/j.ocecoaman.2010.06.015

Ghermandi, A. (2015). Benefits of coastal recreation in Europe: identifying trade-offs and priority regions for sustainable management. Journal of Environmental Management, 152, 218-229. https://doi.org/10.1016/j.jenvman.2015.01.047

Giannakopoulos, C., Kostopoulou, E., Varotsos, K., Tziotziou, K., \& Plitharas, A. (2011). An integrated assessment of climate change impacts for Greece in the near future. Regional Environmental Change, 11(4), 829-843. https://doi.org/10.1007/s10113-011$\underline{0219-8}$ 
Grydehøj, A., \& Kelman, I. (2017). The eco-island trap: climate change mitigation and conspicuous sustainability. Area, 49(1), 106-113. https://doi.org/10.1111/area.12300

Hay, J.E. (2013). Small island developing states: coastal systems, global change and sustainability. Sustainability Science, 8(3), 309-326. https://doi.org/10.1007/s11625$\underline{013-0214-8}$

Holmberg, J. (1998). Backcasting: a natural step in operationalising sustainable development. Greener Management International, 23, 30-51.

Kelly, R.A., Jakeman, A.J., Barreteau, O., Borsuk, M.E., ElSawah, S., Hamilton, S.H, Henriksen, H.J., Kuikka, S., Maier, H.R., Rizzoli, A.E., Delden, H., \& Voinov, A.A. (2013). Selecting among five common modelling approaches for integrated environmental assessment and management. Environmental Modelling E Software, 47, 159-181. https://doi.org/10.1016/j.envsoft.2013.05.005

Kontogianni, A., Kavakli Z., Avagianou, E., \& Tsirtsis, G. (2007). Implementation of integrated scenario analysis and modelling for the sustainable development of a coastal area in Eastern Mediterranean. Transitional Waters Monographs, 1, 93-105.

Kostopoulou, E., \& Jones, P.D. (2005). Assessment of climate extremes in the Eastern Mediterranean. Meteorology and Atmospheric Physics, 89(1-4), 69-85. https://doi.org/10.1007/s00703-005-0122-2

Kostopoulou, E., Giannakopoulos, C., Hatzaki, M., Karali, A., Hadjinicolaou, A., Lelieveld, J., \& Lange, M.A. (2014). Spatio-temporal patterns of recent and future climate extremes in the Eastern Mediterranean and Middle East Region. Natural Hazards and Earth System Sciences, 14(6), 1565-1577. https://doi.org/10.5194/nhess-14-15652014

Krelling, A.P., Polette, M., \& DelValls, A.C. (2008). CoastLearn: lessons learnt from a webbased capacity building in integrated coastal zone management (ICZM). Ocean \& Coastal Management, 51(12), 789-796. https://doi.org/10.1016/j.ocecoaman.2008.09.005

Le Gentil, E. \& Mongruel, R. (2015). A systematic review of socio-economic assessments in support of Coastal Zone Management (1992-2011). Journal of Environmental Management, 149, 85-96. https://doi.org/10.1016/j.jenvman.2014.10.018

Marotta, L., Ceccaroni, L., Matteucci, G., Rossini, P., \& Guerzoni, S. (2011). A decisionsupport system in ICZM for protecting the ecosystems: integration with the habitat directive. Journal of Coastal Conservation, 15(3), 393-405. https://doi.org/10.1007/s11852-010-0106-3

Moldan, B., Janoušková, S., \& Hák, T. (2012). How to understand and measure environmental sustainability: indicators and targets. Ecological Indicators, 17, 4-13. https://doi.org/10.1016/j.ecolind.2011.04.033

Nadim, F., Bagtzoglou, A.C., \& Iranmahboob, J. (2008). Coastal management in the Persian Gulf Region within the framework of the ROPME Programme of Action. Ocean \& Coastal Management, 51(7), 556-565. https://doi.org/10.1016/j.ocecoaman.2008.04.007

Otter, H.S. (2000). Complex adaptive land use systems-An interdisciplinary approach with agent-based models. Ph.D. thesis, University of Twente, Enschede, The Netherlands.

Perez-Cayeiro, M.L., \& Chica-Ruiz, J.A. (2015). Evaluation of a programme of ntegrated coastal zone management: the Ecoplata Programme (Uruguay). Marine Policy, 51, 527535. https://doi.org/10.1016/j.marpol.2014.09.008

Perz, S.G., Mu-oz-Carpena R., Kiker G., \& Holt, R.D. (2013). Evaluating ecological resilience with global sensitivity and uncertainty analysis. Ecological Modelling, 263, 174-186. https://doi.org/10.1016/j.ecolmodel.2013.04.024 
Petridis, P. (2012). Perceptions, attitudes and involvement of local residents in the establishment of a Samothraki Biosphere Reserve, Greece. Eco Mont-Journal on Protected Mountain Areas Research, 4(1), 59-63. https://doi.org/10.1553/eco.mont-4-1s59

Pickaver, A.H., Gilbert, C., \& Breton, F. (2004). An indicator set to measure the progress in the implementation of integrated coastal zone management in Europe. Ocean $\mathcal{E}$ Coastal Management, 47(9-10), 449-462. https://doi.org/10.1016/j.ocecoaman.2004.06.001

R Core Team (2013). R: a language and environment for statistical computing. R Foundation for Statistical Computing, Vienna, Austria. http://www.R-project.org/

Robinson, J. (2003). Future subjunctive: backcasting as social learning. Futures, 35(8), 839856. https://doi.org/10.1016/S0016-3287(03)00039-9

Rodríguez-Rodríguez, D., \& Martínez-Vega, J. (2012). Proposal of a system for the integrated and comparative assessment of protected areas. Ecological Indicators, 23, 566572. https://doi.org/10.1016/j.ecolind.2012.05.009

Saaty, T.L. (1980). The analytic hierarchy process. New York: McGraw-Hill.

Soriani, S., Buono, F., Tonino, M., \& Camuffo, M. (2015). Participation in ICZM initiatives: critical aspects and lessons learnt from the Mediterranean and Black Sea experiences. Marine Pollution Bulletin, 92(1-2), 143-148. https://doi.org/10.1016/j.marpolbul.2014.12.045

Spilanis, I., Kizos, T., Koulouri, M., Kondyli, J., Vakoufaris, C., \& Gatsis, I. (2009). Monitoring sustainability in insular areas. Ecological Indicators, 9(1), 179-187. https://doi.org/10.1016/j.ecolind.2008.03.003

Spilanis, I., Kizos, T., Vaitis, M., \& Koukourouvli, N. (2013). Measuring the economic, social and environmental performance of European island regions: emerging issues for European and regional policy. European Planning Studies, 21(12), 1998-2019. https://doi.org/10.1080/09654313.2012.722970

Spyropoulou, A., Spatharis, S., Papantoniou, G., \& Tsirtsis, G. (2013). Potential response to climate change of a semi-arid coastal ecosystem in Eastern Mediterranean. Hydrobiologia, 705(1), 87-99. https://doi.org/10.1007/s10750-012-1384-6

Stepanova, O. (2015). Conflict resolution in coastal resource management: comparative analysis of case studies from four European countries. Ocean \& Coastal Management, 103, 109-122. https://doi.org/10.1016/j.ocecoaman.2014.10.017

Stojanovic, T., Ballinger, R.C., \& Lalwani, C.S. (2004). Successful integrated coastal management: measuring it with research and contributing to wise practice. Ocean $\mathcal{E}$ Coastal Management, 47(5-6), 273-298. https://doi.org/10.1016/j.ocecoaman.2004.08.001

Stratford, E. (2008). Islandness and struggles over development: a Tasmanian case study. Political Geography, 27(2), 160-175. https://doi.org/10.1016/j.polgeo.2007.07.007

Uusitalo, L., Lehikoinen, A., Helle, I., \& Myrberg, K. (2015). An overview of methods to evaluate uncertainty of deterministic models in decision support. Environmental Modelling \& Software, 63, 24-31. https://doi.org/10.1016/j.envsoft.2014.09.017

Van Kouwen, F., Dieperink, C., Schot, P., \& Wassen, M. (2008). Applicability of decision support systems for integrated coastal zone management. Coastal Management, 36(1), 19-34. https://doi.org/10.1080/08920750701682007

Varghese, K., Ganesh, L.S., Mani, M., Anilkumar, P.P., Murthy, R., \& Subramaniam, B.R. (2008). Identifying critical variables for coastal profiling in ICZM Planning: a systems approach. Ocean \& Coastal Management, 51(1), 73-94. https://doi.org/10.1016/j.ocecoaman.2007.03.002

Zaldivar, J.M., Solidoro, C., Tsirtsis, G., \& Mouillot, D. (2006). Special issue on southern European coastal lagoons-Preface. Ecological Modelling, 193, 1-3. 
Appendix 1: Simple model equations for the calculation of environmental and socioeconomic indicators.

\begin{tabular}{|c|c|}
\hline Indicator & Equation \\
\hline \multicolumn{2}{|r|}{$\underline{\text { Agriculture }}$} \\
\hline Water consumption & Cultivated area $\mathrm{x} \%$ irrigated $\mathrm{x}$ water consumption/unit area \\
\hline Energy consumption & Cultivated area $\mathrm{x} \%$ irrigated $\mathrm{x}$ energy consumption/unit area \\
\hline $\mathrm{N}, \mathrm{P}$ pollution & From point and non-point sources through a watershed model \\
\hline $\mathrm{CO}_{2}$ emissions & Energy consumption $\times \mathrm{CO}_{2}$ emissions $/ \mathrm{kWh}$ consumed energy \\
\hline Production & Cultivated area $\mathrm{x}$ production/unit area \\
\hline Income & Production $\mathrm{x}$ value/unit of production \\
\hline \multicolumn{2}{|r|}{$\underline{\text { Stock-breeding }}$} \\
\hline Water consumption & Number of animals $\mathrm{x}$ water consumption/animal \\
\hline Energy consumption & Number of animals $\mathrm{x}$ energy consumption/animal \\
\hline $\mathrm{N}, \mathrm{P}$ pollution & Number of animals $\mathrm{x} \mathrm{N}, \mathrm{P}$ /animal \\
\hline $\mathrm{CO}_{2}$ emissions & Energy consumption $\mathrm{x} \mathrm{CO}_{2}$ emissions $/ \mathrm{kWh}$ consumed energy \\
\hline Meat production & Number of animals $x$ meat production/animal \\
\hline Milk production & Number of dairy animals $\mathrm{x}$ milk production/dairy animal \\
\hline Income & $\begin{array}{l}\text { Meat production } \mathrm{x} \text { value/unit of production }+ \text { Milk production } \mathrm{x} \\
\text { value/unit of production }\end{array}$ \\
\hline
\end{tabular}

\section{Fisheries}

Energy consumption Catch $\mathrm{x}$ energy consumption/unit of catch

$\mathrm{N}, \mathrm{P}$ pollution

Catch $\times$ N,P/unit of catch

$\mathrm{CO}_{2}$ emissions

Energy consumption $\mathrm{x} \mathrm{CO}_{2}$ emissions/kWh consumed energy

Income

Catch $\mathrm{x}$ value/unit of catch

\section{Industry}

Water consumption Raw material $\mathrm{x}$ water consumption/unit of raw material

Energy consumption Raw material $\mathrm{x}$ energy consumption/unit of raw material

$\mathrm{N}, \mathrm{P}$ pollution Production $\mathrm{x} \mathrm{N}, \mathrm{P} / \mathrm{unit}$ of production

$\mathrm{CO}_{2}$ emissions Energy consumption $\mathrm{x} \mathrm{CO}_{2}$ emissions/ $\mathrm{kWh}$ consumed energy

Income Raw material $\mathrm{x}$ cost of processing/unit of raw material

\section{Tourism}

Nights spent Number of beds $\mathrm{x}$ nights spent/bed

Water consumption Nights spent $\mathrm{x}$ water consumption/day

Energy consumption Nights spent $\mathrm{x}$ energy consumption/day

$\mathrm{N}, \mathrm{P}$ pollution Nights spent $\mathrm{x}, \mathrm{P} /$ day

$\mathrm{CO}_{2}$ emissions $\quad$ Energy consumption $\mathrm{x} \mathrm{CO}_{2}$ emissions/ $\mathrm{kWh}$ consumed energy

Solid wastes Nights spent $\mathrm{x}$ solid wastes/capita.day

Income Nights spent $\mathrm{x}$ average tourist expenditure/day 


\section{Constructions}

Water consumption Number of employees $\mathrm{x}$ water consumption/capita.day

Energy consumption Number of employees x energy consumption/capita.day

$\mathrm{CO}_{2}$ emissions Number of employees $\times \mathrm{CO}_{2}$ emissions/capita.day

Solid wastes Number of employees $\mathrm{x}$ solid wastes/capita.day

Income Number of employees $\mathrm{x}$ average annual income in constructions

\section{Services}

Water consumption Number of employees $\mathrm{x}$ water consumption/capita.day

Energy consumption Number of employees $\mathrm{x}$ energy consumption/capita.day

$\mathrm{CO}_{2}$ emissions Number of employees $\times \mathrm{CO}_{2}$ emissions/capita.day

Solid wastes Number of employees $\mathrm{x}$ solid wastes/capita.day

Income Number of employees $\mathrm{x}$ average annual income in services

\section{Households}

Water consumption Residents $\mathrm{x}$ water consumption/capita.day

Energy consumption Residents $\mathrm{x}$ energy consumption/capita.day

$\mathrm{N}, \mathrm{P}$ pollution Residents $\mathrm{x}, \mathrm{P} /$ capita.day

$\mathrm{CO}_{2}$ emissions Number of residents $\mathrm{x} \mathrm{CO}_{2}$ emissions/capita.day

Solid wastes Number of residents $\mathrm{x}$ solid wastes/capita.day

\section{Other socieconomic indicators}

Total income Income from all sectors + income from pensions

Employment rate Employed/financially active

Poverty index [Unemployed + (employees in agriculture + employees in stock-breeding)

x $0.2+$ employees in fisheries x 0.3$]$ /financially active

Access to education [1-(employed/financially active) $] \times 0.5$

index

Life expectancy index $0.3 \times$ employment rate $+[0.7 \times$ (employed - employees in fisheries employees in industry) $x 0.3$ employed

HDI $\quad 0.3 \mathrm{x}$ life expectancy index $+0.3 \mathrm{x}(1-$ access to education index $)+0.4 \mathrm{x}$

(1- poverty index)

Appendix 2: Dependencies and feedback mechanisms in scenario testing.

\begin{tabular}{ll}
\multicolumn{1}{c}{ Variable } & \multicolumn{1}{c}{ Equation } \\
\hline Industrial raw material & Related agricultural product (e.g., olives for olive oil, must for wine) \\
Trend in constructions & Last two-years' trend in income and population \\
Trend in services & Last two-years' trend in income \\
Trend in population & Last two-years' trend in income and HDI \\
\hline
\end{tabular}

